\title{
Spiritualitas dan Depresi pada Pasien Kanker
}

\author{
Erwin Wiksuarini ${ }^{1 *}$, Beti Haerani ${ }^{1)}$, Muhammad Amrullah ${ }^{1)}$ \\ Email: erwin.wiksuarini91@gmail.com \\ 1) Universitas Qamarul Huda Badaruddin
}

\begin{abstract}
ABSTRAK
Spiritualitas dapat memberikan pengaruh positif dalam menemukan makna dan tujuan hidup. Penelitian ini bertujuan untuk mengetahui hubungan spiritualitas terhadap depresi pada pasien kanker. Jenis penelitian menggunakan desain deskriptif analitik dengan pendekatan cross sectional dengan teknik total sampling dengan jumlah 100 sampel. Kuesioner yang digunakan adalah Spiritual Well Being dan Beck Depression Inventory II. Analisis data menggunakan uji Pearson. Rata-rata skor spiritualitas adalah 98.84 dan 8.65 untuk depresi. Berdasarkan hasil penelitian didapatkan hasil bahwa spiritualitas secara signifikan berhubungan terhadap depresi dengan nilai $P$ value $0.01<0.05$. Pada penderia kanker diharapkan agar lebih memperhatikan masalah spiritualitas.
\end{abstract}

Kata kunci: Spiritualitas; depresi; kanker

\begin{abstract}
Spirituality can give positive impact to find meaning and purpose in the life. The purpose of this study to know the correlatiom of spirituality with depression in cancer patient. This research method was descriptive analytic with cross sectional approach using total sampling 100 samples. The questionnaire used was Spiritual Well Being and Beck Depression Inventory II. The statistical test is using Pearson test. The mean spirituality score was 98.84 and 8.65 for depression, it showed that spirituality was significantly associated to depression with $\mathrm{P}$ value $0.01<0.05$. So the data about spirituality can be attention.
\end{abstract}

Keywords: Spirituality; depression; cancer

\section{A. LATAR BELAKANG}

Menurut data World Health Organization tahun 2013, kanker merupakan penyakit tidak menular dan penyebab kematian tertinggi nomer dua di dunia setelah penyakit kardiovaskuler dengan angka kejadian 13\%. Pada tahun 2030 diperkirakan insidens kanker dapat mencapai 26 juta orang dan 17 juta di antaranya meninggal akibat kanker [1]. Menurut hasil survei American Cancer Society (ACS) di Amerika, pada tahun 2016 insidens penyakit kanker sekitar 1.685.210 kasus dan sekitar 595.690 orang meninggal akibat kanker [2].

Pada tahun 2013, di Indonesia prevalensi kanker sekitar 1,4 per 1000 penduduk atau sekitar 333.000 orang [3]. Kanker merupakan penyebab kematian no 7 di Indonesia dengan prevalensi tertinggi kanker payudara dan kanker serviks, hal ini disebabkan karena hampir $70 \%$ dari penderita ditemukan dalam keadaan stadium lanjut [1]. Penyakit kanker dan pengobatannya dapat menimbulkan berbagai masalah dalam kehidupan, baik masalah fisik, psikologis, sosial maupun spiritul. Masalah fisik penderita akan mengalami nyeri, insomnia dan kelelahan yang terus-menerus [4]. Kondisi ini akan menyebabkan timbulnya berbagai masalah psikologis seperti perasaan bersalah, kesepian, cemas, stres dan depresi [5].

Depresi pada pasien kanker disebabkan oleh efek samping pengobatan kemoterapi seperti mual muntah, rambut rontok, dan hot flushes [6]. Gejala depresi yang dialami pada pasien kanker seperti merasa putus asa, takut akan kematian 
dan masa depan, tidak bisa menerima kenyataan dan mengalami shock [7]. Dalam penelitian yang dilakukan oleh Suwistianisa yang menemukan bahwa dari 60 pasien dengan kanker payudara, kolon dan tiroid yang mengalami gejala depresi ringan sebanyak $20(33,3 \%)$, depresi sedang sebanyak 23 (38,3\%), dan depresi berat sebanyak $17(28,3 \%)$ [8].

Pada pasien dengan kanker stadium lanjut depresi akan meningkat sejalan dengan keparahan penyakitnya sehingga dapat mengganggu kemampuan pasien untuk mengatasi beban penyakit, menurunkan penerimaan pengobatan, memperpanjang waktu perawatan, meningkatkan resiko bunuh diri dan mengurangi kualitas hidup [9]. Depresi pada pasien kanker disebabkan karena spiritualitas yang rendah [10]. Hal ini disebabkan karena penanganan spiritualitas dan religius koping negatif seperti perasaan ditinggalkan atau dihukum oleh Tuhan, mempertanyakan Tuhan sehingga menyebabkan kualitas hidup yang lebih buruk [11].

Spiritualitas merupakan salah satu respon koping utama pada pasien dengan kanker untuk beradaptasi dengan kehidupan mereka [12]. Spiritualitas dapat dijadikan sebagai salah satu bentuk mekanisme koping positif yang dapat digunakan pada pasien kanker untuk beradaptasi terhadap diagnosis dan pengobatan kanker [13]. Spiritualitas juga dapat menjadi mekanisme koping yang positif dalam melindungi penderita kanker dari gejala depresi [14].

Spiritualitas menjadi sangat penting pada pasien kanker ketika individu mengalami situasi kritis, oleh sebab itu percaya kepada Tuhan atau kekuatan yang lebih tinggi dapat mengatasi masalah yang ditimbulkan oleh penyakit kanker [15]. Spiritualitas yang baik dapat membuat individu menerima penyakit yang dialaminya, merasakan kedekatan dengan Tuhan dan tidak menyalahkan Tuhan tetapi menganggap sakit itu adalah anugerah dari Tuhan, memiliki rasa cinta dan nyaman, dukungan sosial dapat memberi motivasi untuk sembuh dan kuat dalam menjalani hidup sehingga dapat menciptakan kesejahteraan yang dapat meningkatkan kualitas hidup [16].

Hasil penelusuran literatur, penelitian terkait spiritualitas pada pasien dengan kanker di Indonesia sudah ada tetapi masih terbatas sehingga penulis tertarik untuk melakukan penelitian tentang hubungan tingkat spiritualitas dengan depresi pada pasien dengan kanker di RSUD Provinsi NTB.

\section{B. METODE PENELITIAN}

Dalam penelitian ini menggunakan metode kuantitatif yang bersifat deskriptif analitik dengan pendekatan cross sectional, yaitu jenis penelitian yang menekankan pada waktu pengukuran atau observasi data variabel hanya satu kali, pada satu saat dan dapat memberi informasi atau gambaran analisis situasi yang ada pada satu waktu [17].

Populasi dalam penelitian ini adalah seluruh pasien kanker yang menjalani rawat inap di RSUD Provinsi NTB dengan jumlah kunjungan rata-rata pasien dalam satu bulan sebanyak 61 orang. Sampel dalam penelitian ini adalah pasien kanker dewasa dengan menggunakan teknik pengambilan sampel total sampling yaitu teknik pengambilan sampel dengan cara memilih semua populasi menjadi sampel yang telah memenuhi kriteria inklusi dan eksklusi. Kriteria inklusi dalam penelitian ini adalah pasien kanker yang bersedia menjadi responden, usia 18 tahun sampai 75 tahun, stadium III dan IV. Kriteria eksklusi dalam penelitian ini adalah pasien yang mengalami penurunan kesadaran, gangguan jiwa dan tidak komunikatif. Pengumpulan data dalam penelitian ini menggunakan kuesioner yang dilakukan pada bulan Maret sampai April 2021 dengan jumlah sampel sebanyak 117 responden namun ada 11 responden yang menolak untuk dijadikan responden, 6 orang berhenti saat pengisian kuesioner sehingga total sampel yang memenuhi kriteria inklusi sebanyak 100 orang dengan respon rate $85,47 \%$.

Instrumen yang digunakan untuk mengukur spiritualitas pada pasien kanker dalam penelitian ini menggunakan Spiritual Well Being Scale 
(SWBS) dalam versi Bahasa Indonesia. Instrumen SWBS terdiri dari dua subskala yaitu Religious Well Being (RWB) dan Extensional Well Being (EWB) yang dibagi menjadi 10 item pernyataan untuk Religious Well Being (RWB) dan 10 item pernyataan untuk Extensional Well Being (EWB) sehingga total item pernyataan Spiritual Well Being terdiri dari 20 item pernyataan. Setiap item pernyataan memiliki skor 1-6 dengan skor total berkisar dari 20-120 yang dinilai berdasarkan skala Likert [18].

Instrumen yang digunakan untuk mengukur tingkat depresi dalam penelitian ini menggunakan Beck Depression Inventory II yang dikembangkan oleh Beck pada tahun 1996 untuk mengukur tingkat depresi pada pasien yang berusia 13 tahun atau lebih. Instrumen ini terdiri dari 21 item pernyataan dengan skor total 0-63 dengan masing-masing item pernyataan diberi skor 0 sampai 3 yang menggambarkan dari tidak adanya gejala sampai adanya gejala yang paling berat.

\section{HASIL DAN PEMBAHASAN}

Berdasarkan hasil penelitian didapatkan karakteristik responden dalam penelitian ini dapat dilihat pada tabel 1 di bawah ini.

Tabel 1. Karakteristik Data Demografi

\begin{tabular}{ll}
\hline Karakteristik & Frekuensi (\%) \\
\hline $\begin{array}{l}\text { Umur (Mean } \pm \text { SD) } \\
\quad \text { Min-Max) }\end{array}$ & $\begin{array}{l}(44.68 \pm 10.964) \\
(20-75)\end{array}$ \\
\hline $\begin{array}{l}\text { Jenis Kelamin } \\
\text { Laki-laki }\end{array}$ & $19(19 \%)$ \\
Perempuan & $81(81 \%)$ \\
\hline Agama & \\
Islam & $91(91 \%)$ \\
Hindu & $6(6 \%)$ \\
Kristen & $2(2 \%)$ \\
Katolik & $1(1 \%)$ \\
\hline Pendidikan & \\
Tidak Sekolah & $20(20 \%)$ \\
SD & $13(13 \%)$ \\
SLTP & $27(27 \%)$ \\
SMA & $21(21 \%)$ \\
DIII & $1(1 \%)$ \\
S1 & $6(6 \%)$ \\
S2 & $2(2 \%)$ \\
\hline Pekerjaan &
\end{tabular}

\begin{tabular}{ll}
\hline Bekerja & $18(18 \%)$ \\
Tidak Bekerja & $82(82 \%)$ \\
\hline Stadium Kanker & \\
Stadium III & $82(82 \%)$ \\
Stadium IV & $18(18 \%)$ \\
\hline Jenis Kanker & \\
Kanker Payudara & $56(56 \%)$ \\
Kanker Ovarium & $10(10 \%)$ \\
Kanker Nasofaring & $16(16 \%)$ \\
Kanker Serviks & $6(6 \%)$ \\
Kanker Kolon & $6(6 \%)$ \\
Lain-lain & $6(6 \%)$ \\
\hline Lama Diagnosis & \\
1- 3 bulan & $14(14 \%)$ \\
$>3$ bulan & $86(86 \%)$ \\
\hline Kemoterapi & \\
Ya & $94(94 \%)$ \\
Tidak & $6(6 \%)$ \\
\hline Ibadah & \\
Selalu & $95(95 \%)$ \\
Sering & $2(2 \%)$ \\
Kadang-kadang & $3(3 \%)$ \\
\hline
\end{tabular}

Berdasarkan tabel 1 dapat dilihat rata-rata responden berumur 44 tahun, sebagian besar berjenis kelamin perempuan yaitu 81 orang $(81 \%)$, beragama Islam 91 orang $(91 \%)$, berpendidikan SLTP yaitu 27 orang (27\%), tidak bekerja yaitu 82 orang (82\%), stadium III yaitu 82 orang $(82 \%)$, didiagnosis kanker payudara yaitu 56 orang (56\%), diagnosis lebih dari 3 bulan yaitu 86 orang $(86 \%)$, dan 95 orang $(95 \%)$ selalu melakukan ibadah.

Tabel 2. Spiritualitas dan Depresi pada Pasien Kanker di RSUD Provinsi NTB

\begin{tabular}{lll}
\hline Variabel & Mean \pm SD & (Min-Max) \\
\hline RWB & $51.08 \pm 6.893$ & $36-60$ \\
EWB & $47.72 \pm 6.978$ & $34-60$ \\
SWB & $98.84 \pm 13.243$ & $72-120$ \\
Depresi & $8.65 \pm 6.531$ & $0-30$ \\
\hline
\end{tabular}

Pada tabel 2 menunjukkan bahwa tingkat spiritualitas pada pasien kanker dalam penelitian ini sangat tinggi yaitu 98.84 khususnya pada skor religious well being, sedangkan tingkat depresi pada didapatkan rata-rata depresi rendah yaitu 8.65 . 
Tabel 3. Hubungan spiritualitas dengan depresi pada pasien kanker di RSUD Provinsi NTB

\begin{tabular}{lcc}
\hline Variabel & \multicolumn{2}{c}{ Depresi } \\
\cline { 2 - 3 } & $\mathrm{R}$ & $P$ value \\
\hline RWB & -0.702 & 0.01 \\
EWB & -0.776 & 0.01 \\
SWB & -0.774 & 0.01 \\
\hline
\end{tabular}

Pada tabel 3 di atas menunjukkan bahwa hasil analisis statistik menggunakan uji Pearson didapatkan hubungan yang signifikan antara spiritualitas terhadap depresi dengan arah korelasi negatif yang kuat, artinya semakin tinggi tingkat spiritualitas maka depresi semakin menurun.

Spiritualitas pada pasien kanker dalam penelitian ini memiliki rata-rata spiritual well being yang tinggi dengan rata-rata tingkat religious well being lebih tinggi dari pada tingkat existential well being, hal ini dikaitkan dengan latar belakang budaya dan agama di Lombok yang umumnya religius dan cenderung beralih ke agama ketika menghadapai situasi krisis dan stres. Hasil penelitian ini sejalan dengan Mohebbifar tahun 2015 di Iran yang menemukan bahwa rata-rata tingkat religious well being lebih tinggi dari pada existential well being [19].

Spiritualitas yang tinggi pada penelitian ini berkaitan dengan karakteristik data demografi yang sebagian besar beragama Islam, hal ini di dukung oleh penelitian Effendy tahun 2015 yang menyatakan mayoritas orang Indonesia adalah Muslim, agama memainkan peran penting dalam kehidupan sehari-hari mereka, dimana penyakit dianggap sebagai kehendak Tuhan dan kematian ditakdirkan oleh Tuhan, yang membuatnya lebih mudah bagi mereka untuk menerima penyakit mereka [20].

Hasil yang sama ditemukan dalam penelitian Al-Natour tahun 2017 di Iran menemukan bahwa pada pasien kanker payudara yang mayoritas beragama Muslim memiliki kesejahteraan spiritual yang tinggi [21]. Hasil ini didukung oleh Jafari tahun 2013 yang menyatakan bahwa menjadi seorang Muslim memiliki kepercayaan yang tinggi dalam subskala kesejahteraan spiritual, hal ini berkaitan dengan kepercayaan dan keyakinan agama Islam sehingga berkontribusi pada kesejahteraan spiritual secara keseluruhan [22]. Hasil ini diperkuat oleh Rochmawati tahun 2018 bahwa agama/ spiritualitas merupakan salah satu aspek penting dalam kehidupan yang dapat mempengaruhi kondisi kesehatan seseorang [23].

Spiritualitas yang tinggi dalam penelitian ini juga disebabkan karena sebagian besar pasien sudah bisa menerima dan menjalani penyakitnya dengan penuh rasa syukur dan pasrah kepada Tuhan sebagai bagian dari takdir Tuhan yang harus dijalani. Hasil penelitian ini di perkuat oleh Rahnama tahun 2015 di Iran yang menemukan bahwa keyakinan dan kepercayaan agama yang kuat dengan menganggap penyakit dan kesembuahan sudah menjadi kehendak Tuhan dapat menjadi sumber harapan dalam menghadapi penyakit [24].

Depresi dalam penelitian ini rata-rata memiliki skor depresi yang rendah yaitu mengalami gejala depresi minimal atau tidak depresi (tabel 2). Hasil penelitian ini sesuai dengan penelitian Guntari tahun 2016 di RSUP Sanglah Denpasar yang menemukan bahwa pasien kanker payudara post mastektomi sebagian besar mengalami depresi minimal atau normal yaitu sebesar 56\% [25], namun hal yang berbeda dengan hasil penelitian yang ditemukan oleh Rini tahun 2013 di RSUD Prof Margono Soekarjo Purwokerto yang menemukan bahwa depresi pada pasien kanker sebagian besar mengalami depresi berat yaitu 78.8\% [6].

Gejala depresi yang rendah dalam penelitian ini disebabkan karena sebagian besar pasien sudah menderita kanker lebih dari 3 bulan dan sudah bisa menerima penyakit yang dialami saat ini. Hasil penelitian ini sejalan dengan penelitian Bai tahun 2014 di Amerika Serikat yang menyatakan bahwa diagnosis kanker stadium lanjut dalam 1 sampai 3 bulan sejak didiagnosis kanker mengalami depresi, krisis eksistensial dan penurunan kualitas hidup dan akan normal kembali setelah 6 bulan pasca diagnosis kanker [26]. Menurut penelitian yang dilakukan oleh Mass tahun 2015 di Belanda dengan responden sebanyak 12.499 pasien kanker payudara mengalami gejala depresi bervariasi dari $9,4 \%$ hingga $66,1 \%$ dengan skor rata-rata gejala depresi yang tinggi pada wanita umumnya sekitar satu tahun setelah diagnosis dan akan normal kembali dari waktu ke waktu [5].

Berdasarkan tabel 3 menunjukkan bahwa terdapat hubungan yang signifikan antara skor spiritualitas terhadap depresi dengan arah korelasi negatif yang kuat, artinya semakin tinggi skor spiritualitas maka skor depresi semakin menurun. Hasil penelitian ini sesuai dengan 
beberapa penelitian sebelumnya yang menemukan bahwa spiritualitas dan depresi memiliki hubungan negatif yang kuat [26, 27]. Spiritualitas dapat menjadi mekanisme koping positif untuk beradaptasi terhadap penyakit dalam menurunkan gejala depresi ${ }^{[14]}$. Spiritual yang positif juga dapat menjadi strategi penanganan dalam penerimaan terhadap penyakit kanker [28]. Spiritualitas pada pasien kanker memiliki pengaruh yang positif terhadap depresi dalam mencari kekuatan untuk menerima dan menghadapi penyakit kanker sehingga individu yang memiliki kesejahteraan spiritual dapat mempengaruhi kualitas hidup yang lebih baik [29].

\section{KESIMPULAN}

Dalam penelitian ini dapat disimpulkan bahwa spiritualitas pada pasien kanker rata-rata memiliki spiritualitas yang tinggi terutama dalam religious well being dan gejala depresi yang rendah. Spiritualitas dan depresi dalam penelitian ini memiliki hubungan yang kuat dengan arah korelasi negatif, artinya semakin tinggi tingkat spiritualitas maka depresi semakin menurun.

Bagi pelayanan kesehatan agar lebih memperhatikan masalah kesehatan spiritualitas pada pasien kanker dengan cara memberikan pelatihan pada tenaga kesehatan untuk mengkaji dan menangani masalah spiritualitas pada pasien kanker.

\section{E. UCAPAN TERIMA KASIH}

Sumber pendanaan dalam pelaksanaan penelitian ini adalah dana pribadi. Terimakasih kami ucapkan untuk segenap karyawan RSUD Provinsi NTB yang telah membantu penelitian ini.

\section{DAFTAR PUSTAKA}

[1] Kemenkes RI. (2015). Kanker Pembunuh Papan Atas. Mediakom. Edisi 55

[2] American Cancer Society. (2016). Cancer Facts \& Figures 2016. Cancer Facts \& Figures 2016 , $1-9$.
https://doi.org/10.1097/01.NNR.00002895 03.22414.79

[3] Badan Penelitian dan Pengembangan Kesehatan. (2013). Riset Kesehatan Dasar (RISKESDAS) 2013. Laporan Nasional 2013, 1-384. https://doi.org/1 Desember 2013

[4] Ancoli-israel, S., Liu, L., Rissling, M., Natarajan, L., \& Ariel, B. (2015). NIH Public Access, 22(9), 2535-2545. https://doi.org/10.1007/s00520-0142204-5. Sleep

[5] Maass, S. W. M. C., Roorda, C., Berendsen, A. J., Verhaak, P. F. M., \& de Bock, G. H. (2015). The prevalence of long-term symptoms of depression and anxiety after breast cancer treatment: A systematic review. Maturitas, 82(1), 100-108. https://doi.org/10.1016/j.maturitas.2015.04. 010.

[6] Rini, T., Setyaningsih, B., \& Wijayana, K. A. (2013). Faktor-Faktor Yang Berhubungan Dengan Tingkat Depresi, 6, 408-414.

[7] Lindberg, P., Koller, M., Steinger, B., Lorenz, W., Wyatt, J. C., Inwald, E. C., \& Klinkhammer-Schalke, M. (2015). Breast cancer survivors' recollection of their illness and therapy seven years after enrolment into a randomised controlled clinical trial. BMC cancer, 15(1), 554.

[8] Suwistianisa, R., Huda, N., \& Ernawaty, J. (2015). Faktor-Faktor yang Mempengaruhi Tingkat Depresi pada Pasien Kanker yang Dirawat di RSUD.

[9] Arifin Achmad Provinsi Riau. Jurnal Online Mahasiswa Program Studi Ilmu Keperawatan Universitas Riau, 2(2), 14631473.

[10] Krebber, A. M. H., Buffart, L. M., Kleijn, G., Riepma, I. C., De Bree, R., Leemans, C. R., Verdonck-De Leeuw, I. M. (2014). Prevalence of depression in cancer patients: A meta-analysis of diagnostic interviews and self-report instruments. PsychoOncology, 23(2), 121130. https://doi.org/10.1002/pon.3409.

[11] Bovero, A., Leombruni, P., Miniotti, M., Rocca, G., \& Torta, R. (2016). Spirituality, quality of life, psychological adjustment in terminal cancer patients in hospice. European Journal of Cancer Care, 25(6), 961-969. https://doi.org/10.1111/ecc.12360 
[12] Zamanian, H., Eftekhar-Ardebili, H., Eftekhar-Ardebili, M., Shojaeizadeh, D., Nedjat, S., Taheri-Kharameh, Z., \& Daryaafzoon, M. (2015). Religious coping and quality of life in women with breast cancer. Asian Pacific Journal of Cancer Prevention, 16(17), 7721-7725. https://doi.org/10.7314/APJCP.2015.16.17. 7721.

[13] Peteet, J. R., \& Balboni, M. J. (2013). Spirituality and religion in oncology. CA: $A$ Cancer Journal for Clinicians, 63(4), 280289. https://doi.org/10.3322/caac.21187.

[14] Khodaveirdyzadeh, R., Rahimi, R., Rahmani, A., Kodayari, N., \& Eivazi, J. (2016). Spiritual / Religious Coping Strategies and their Relationship with Illness Adjustment among Iranian Breast Cancer Patients, 17, 4097-4101.

[15] Gonzalez, P., Castañeda, S. F., Dale, J., Medeiros, E. A., Buelna, C., Nuñez, A., Talavera, G. A. (2014). Spiritual well-being and depressive symptoms among cancer survivors. Supportive Care in Cancer: Official Journal of the Multinational Association of Supportive Care in Cancer, 22(9),2393-400. https://doi.org/10.1007/s00520-0142207-2

[16] Bhatnagar, S., Gielen, J., Satija, A., Singh, S. P., Noble, S., \& Chaturvedi, S. K. (2017). Signs of spiritual distress and its implications for practice in Indian Palliative Care. Indian Journal of Palliative Care, 23(3), 306.

[17] Nursalam (2016). Metodelogi Penelitian Ilmu dan Keperawatan. Jakarta: Salemba Medika.

[18] Paloutzian, R., Bufford, R., \& Wildman, A. (2012). Spiritual well-being scale: Mental and physical health relationship. In $\mathrm{M}$. Cobb, C. Puchalski, \& B. Rumbold (Eds.), Oxford Textbook of Spirituality in Healthcare. New York: Oxford University Press.

[19] Mohebbifar, R., Pakpour, A. H., Nahvijou, A., \& Sadeghi, A. (2015). Relationship between spiritual health and quality of life in patients with cancer. Asian Pacific Journal of Cancer Prevention, 16(16), 7321-7326.

[20] Effendy, C., Vissers, K., Osse, B. H. P., Tejawinata, S., Vernooij-Dassen, M., \&
Engels, Y. (2015). Comparison of Problems and Unmet Needs of Patients with Advanced Cancer in a European Country and an Asian Country. Pain Practice, 15(5), 433-440.

[21] Al-Natour, A., Al Momani, S. M., \& Qandil, A. M. A. (2017). The Relationship Between Spirituality and Quality of Life of Jordanian Women Diagnosed with Breast Cancer. Journal of Religion and Health, 56(6), 2096-2108. https://doi.org/10.1007/s10943-017-0370-8

[22] Jafari, N., Zamani, A., Farajzadegan, Z., Bahrami, F., Emami, H., \& Loghmani, A. (2013). The effect of spiritual therapy for improving the quality of life of women with breast cancer: a randomized controlled trial. Psychology, health \& medicine, 18 (1), 56-69.

[23] Rochmawati, E., Wiechula, R., \& Cameron, K. (2018). Centrality of spirituality/religion in the culture of palliative care service in Indonesia: An ethnographic study. Nursing \& Health Sciences, (November 2017), 1-7. https://doi.org/10.1111/nhs.12407

[24] Rahnama, M., Khoshknab, M. F., Seyed, B. M. S., Ahmadi, F., \& Arbabisarjou, A. (2015). Religion as an alleviating factor in Iranian cancer patients: a qualitative study. Asian Pacific journal of cancer prevention: APJCP, 16(18), 8519.

[25] Guntari, S., Agung, G., \& Suariyani, N. L. P. (2016). Gambaran Fisik dan Psikologis Penderita Kanker Payudara Post Mastektomi di RSUP Sanglah Denpasar Tahun 2014. Archive of Community Health, 3(1), 24-35.

[26] Bai, M., Lazenby, M., Jeon, S., Dixon, J., \& McCorkle, R. (2014). Exploring the relationship between spiritual well-being and quality of life among patients newly diagnosed with advanced cancer. Palliative \& Supportive Care, (1976), 1-9. https://doi.org/10.1017/S147895151400082 0.

[27] Stutzman, H., \& Abraham, S. (2017). A Correlational Study of Spiritual Well-being and Depression in the Adult Cancer Patient. The Health Care Manager, 36(2), 164-172. https://doi.org/10.1097/HCM.00000000000 00153.

[28] Chaar, E. A., Hallit, S., Hajj, A., Aaraj, R., Kattan, J., Jabbour, H., \& Khabbaz, L. R. 
(2018). Evaluating the impact of spirituality on the quality of life, anxiety, and depression among patients with cancer: an observational transversal study. Supportive Care in Cancer, 1-10.

[29] Gall, T. L., \& Bilodeau, C. (2017). "Why me?"-women's use of spiritual causal attributions in making sense of breast cancer. Psychology and Health, 32(6), 709727.

https://doi.org/10.1080/08870446.2017.129 3270 